\title{
Fluorescent Lewis Adducts: A Practical Guide to Relative Lewis Acid- ity
}

Jordan N. Bentley, Seja A. Elgadi, Joshua R. Gaffen, Paul Demay-Drouhard, Thomas Baumgartner*, and Christopher B. Caputo*

Department of Chemistry, York University, 4700 Keele Street, Toronto, ON M3J 1P3, Canada

KEYWORDS: Lewis acids, sensing, fluorescence, boranes, group 13, group 14, group 15, dithienophosphole

\begin{abstract}
Experimentally determining the strength of a Lewis acid is a highly desirable and important task that has implications across the chemical sciences. Recently, we developed a new fluorescence-based method to evaluate the acidity of a small series of Lewis acids across the p- and d-blocks of the periodic table with great precision. In the present report, we considerably expand the scope of the Fluorescent Lewis Adduct (FLA) method by systematically investigating the strength of over 50 Lewis acids in toluene. Notably, a number of the investigated Lewis acids have never been experimentally measured before. Our refined guide, that now also alleviates the uncertainties that we identified with our original method, clearly shows that the FLA method is robust, accurate, and simple. It shows extreme sensitivity to small structural or electronic perturbations and can account for aggregation or dissociation events that occur in solution.
\end{abstract}

\section{Introduction}

One hundred years after initially defined as electron-pair acceptors, ${ }^{1}$ Lewis acids remain of significant importance in the chemical sciences. However, unlike their Brønsted acid counterparts, there are multiple methods to measure the strength of a Lewis acid. This is in part due to the definition that Lewis used to define an acid simply as an electron pair acceptor, which does not consider the fact that Lewis acidity can be derived from scenarios that involve empty p- or $\mathrm{d}$-orbitals; and this concept has begun to evolve with the discovery of potent Lewis acids with energetically accessible $\sigma^{*}$-orbitals. ${ }^{2-4}$ As such, different analyses are required, as not all Lewis acids will respond in the same way to all methods.

From a practical standpoint, Lewis acids have been pivotal to a range of research fields. The recent renaissance in main group chemistry has established their increasing utility as reagents, ${ }^{5}$ catalysts, ${ }^{6}$ functional materials, and sensors. ${ }^{7}$ Notable successes in metal-free catalysis have shown that main group Lewis acids are useful alternatives to transition metal catalysts. Representative examples in this context include the hydrosilylation or hydrogenation of unsaturated substrates, ${ }^{8}$ as well as the direct $\mathrm{C}-\mathrm{H}$ borylation of aromatic molecules. ${ }^{9}$ As new Lewis acids derived from p-block elements, transition metals, or more exotic scaffolds are being realized, it is critical to evaluate their Lewis acidity, as it has direct implications on their functionality and applicability.

Currently, the predominant experimental method for measuring Lewis acidity is the Gutmann-Beckett method (GB; Scheme 1), ${ }^{10,11}$ which uses $\mathrm{Et}_{3} \mathrm{PO}$ as a probe; the Lewis acid strength is evaluated via a downfield shift in the ${ }^{31} \mathrm{P}$ NMR spectrum. Another common NMR-
Gutmann Beckett:

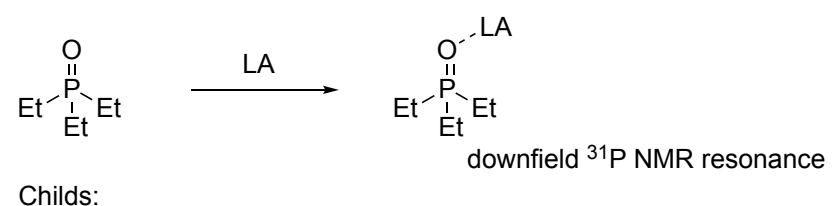

Childs:

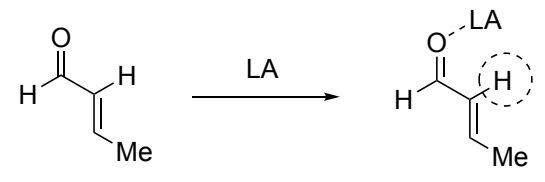

downfield ${ }^{1} \mathrm{H}$ NMR resonance

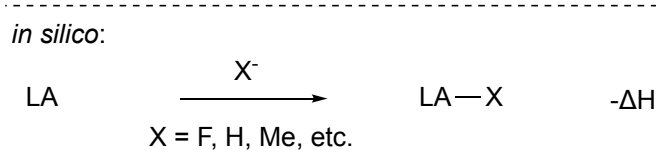

FLA:

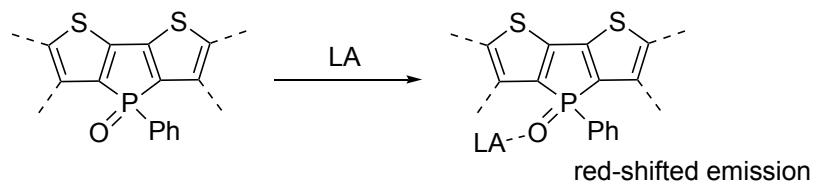

Scheme 1. Established methods for Lewis acid (LA) strength determination.

spectroscopic method is the Childs method that similarly uses crotonaldehyde as a probe via ${ }^{1} \mathrm{H}$ NMR analysis. ${ }^{12}$ Moreover, in silico methods, such as fluoride-ion affinity (FIA) have become popular due to their relative ease of use, ${ }^{13,14}$ but recently, hydride-, methyl-, and other ion affinities have also been explored as complementary 
scales. ${ }^{15}$ Of late, the global electrophilicity index (GEI) has been proposed as an in silico analysis that combines several calculated metrics to provide an overall Lewis acidity value. ${ }^{16}$ While these experimental and computational methods are robust and widely accepted, they suffer from the drawback that they measure the Lewis acidity of a defined molecular species. In solution, the true nature of the Lewis acid may be different, as aggregation or dissociation effects may occur. These are particularly problematic for group 13 halides $\left(\mathrm{AlCl}_{3}\right.$ for example) where the Guttman-Beckett method indicates there are multiple species in solution so a true acceptor number cannot be determined (See SI). Therefore, obtaining a measurement of the apparent Lewis acidity a given solution would be highly beneficial in terms of practical applications.

We recently reported a new method that eliminates some of these issues. ${ }^{17}$ Our method leverages the bathochromic shift of a series of luminescent Lewis-basic probes upon adduct formation with Lewis acids, which we termed Fluorescent Lewis Adducts (FLAs, Scheme 1 bottom). The observed red shift of the dithienophosphole oxide probes is the result of a lowered LUMO energy ( $\pi^{*}$ character) upon Lewis-acid coordination, induced by a change in polarity of the exocyclic $\mathrm{P}-\mathrm{O}$ bond. The strength of a Lewis acid directly impacts the energy level of the $\mathrm{P}-\mathrm{O} \sigma^{*}$ orbital, which is a major contributor to the dithienophosphole LUMO. This $\sigma^{*}-\pi^{*}$ interaction is well established as key-electronic component in conjugated phosphole-based materials. $^{18}$

Our method also avoids the use of a singular Lewis base, by measuring Lewis acidity in solution against a series of dithienophosphole oxide $(\mathrm{P}=\mathrm{O})$ probes with different basicities. It should be noted that the basicity of the dithienophosphole oxide probes is altered, at least to some extent, as the $\pi$-conjugation changes. ${ }^{17}$

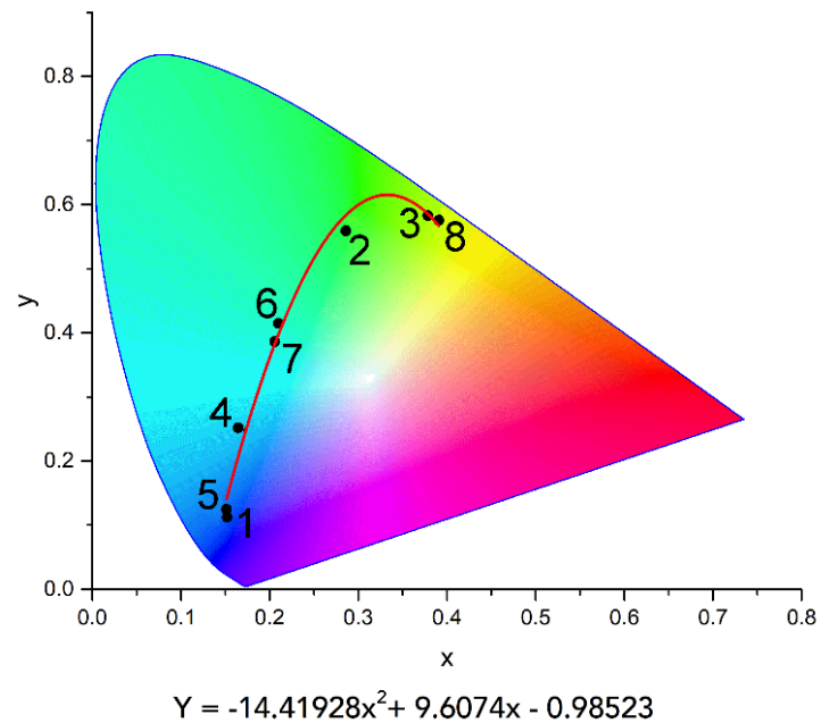

Figure 1. CIE diagram overlaid with the parabolic fit for the eight dithienophosphole probes.

By evaluating the chromaticity of the resulting FLAs, we discovered a strong correlation between Lewis acidity and their respective commission internationale de l'éclairage (CIE) coordinates. In our initial report, we analyzed 15 Lewis acids, whose relative strength was determined against three Lewis-basic dithienophosphole oxide probes, and quantified as arbitrary Lewis acid units (LAU).${ }^{17}$ Using this approach, we were able to accurately compare classical main-group, cationic, and transition-metal-based Lewis acids on the same scale for the first time. Notwithstanding, our method ultimately revealed a few uncertainties over time, specifically around three points: $i)$ the use of only three Lewis bases led to larger than desirable error margins; ii) the small window of defined LAU values for the measured Lewis acids made it difficult to assess differences between species of similar strength; and iii) some of the FLAs with strong Lewis acids were found to emit into the near-IR region, which is outside the defined chromaticity space.

Building on our initial proof-of-concept study, we now expand the scope of this method as we push towards developing a robust fluorescence-based method to measure the effective acidity, or strength for that matter, of Lewis acids against dithienophosphole oxidebased probes in a given solution. Herein, we report the improvement of our methodology to confront the issues above, significantly expand the scope of the investigated Lewis acids, and comment on possible limitations to keep in mind when interpreting the data.

\section{Results and Discussion}

\section{Original Methodology}

The chromaticity/CIE coordinates of the FLAs are the cornerstone of our method, since chromaticity is determined directly from the emission spectrum of a given compound (i.e., via the integral under the curve). The universal CIE space is defined within the visible spectrum ( $380 \mathrm{~nm}$ to $780 \mathrm{~nm}$ ), or in other words, the colors that the human eye can see. Each color is defined by the unitless variables $\mathrm{x}$, $\mathrm{y}$, and $\mathrm{z}$ that describe a color as a function of hue, saturation, and intensity (Figure 1). To eliminate the dependency on a single Lewis base, we used six dithienophosphole oxide probes with different emission colors (1-6, Figure 2) whose CIE coordinates could be fit parabolically (Figure 1). The obtained parabolic function expresses the CIE coordinates of any given dithienophosphole oxide probe, and a similar parabolic fitting approach was used for the resulting FLA chromaticities with each Lewis acid. With these two functions in hand, we concluded that the intercept of the two functions describes an ideal FLA binding pair. ${ }^{17}$

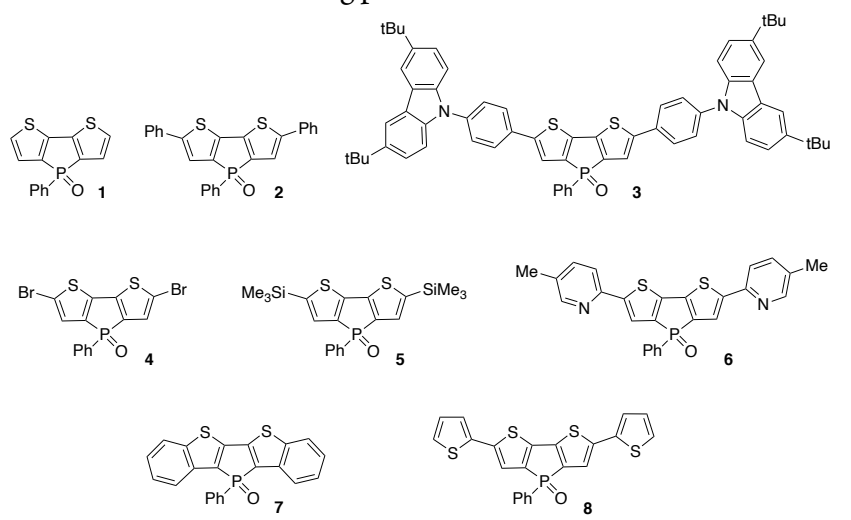

Figure 2. Dithienophosphole oxide probes 1-8 used in this work.

Based on prior titration results, we ascertained that the intercept of these two parabolic functions represents the chromaticity of a theoretical "ideal" Lewis acid-base combination whereby the binding constant is the one at their equilibrium point. Extrapolating the $\mathrm{x}$ coordinate from this intercept provided us a relative Lewis acid scale (in arbitrary Lewis acid units, LAUs) to compare the original 15 Lewis acids (Figure 3a). It should be mentioned in this context that the obtained LAU values represent the apparent Lewis acidity of a 
given species in solution (here: toluene) against the dithienophosphole oxide probes. This is irrespective of the actual structure of the Lewis acid, given that aggregation and dissociation phenomena may occur. In other words, each LAU represents how strong a given Lewis acid is in that solution against our class of emissive probes.
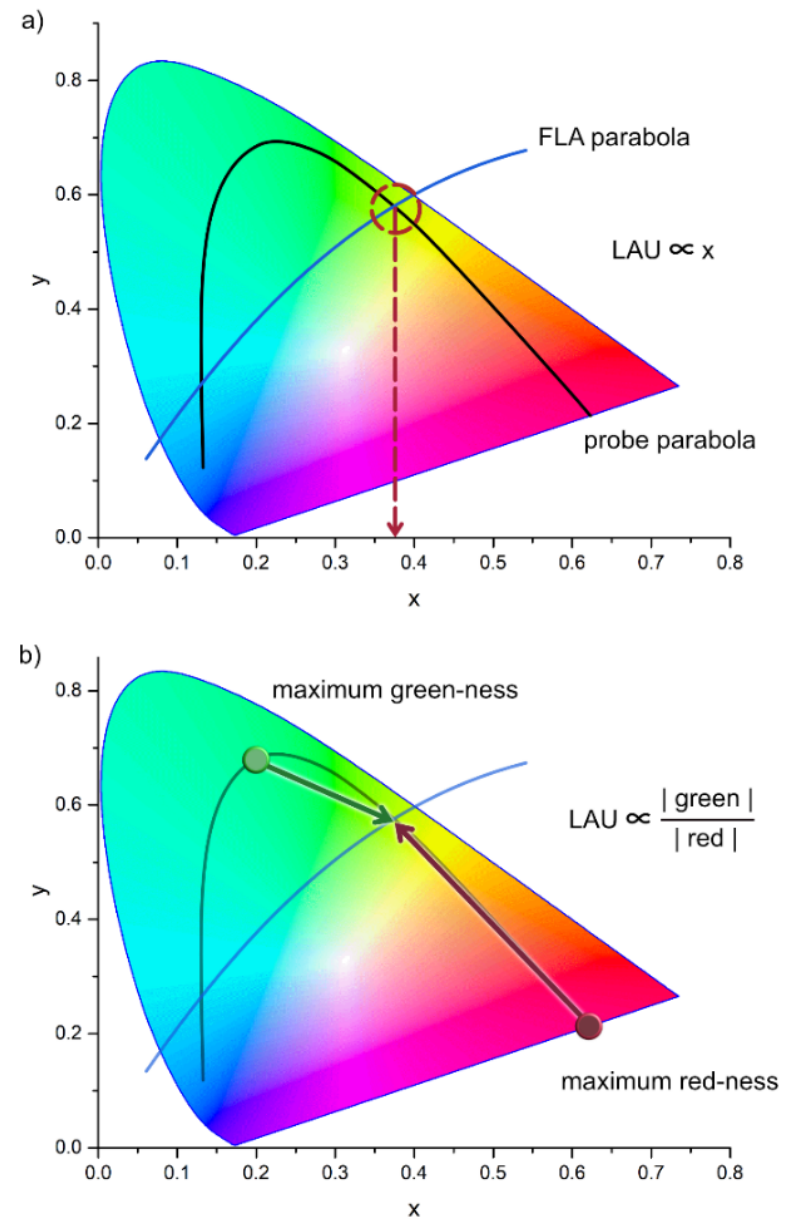

Figure 3. FLA method a) original (LAU range: 0.5 - 1.0); b) improved (LAU range: $0->50$ ).

\section{Improved Methodology}

Since three points are mathematically the minimum necessary to define a parabola, experimental error could unfortunately not be discussed in the original work. We resolved this issue by acquiring the chromaticities of the FLAs with additional probes. To improve the fit of the free-probe parabola and to minimize the potential uncertainties as much as possible, we included additional probes in the original report (1-6; Figure 2) and two more probes as part of this study $(\mathbf{7 , 8})$. To this end, we used the benzo-fused dithienophosphole oxide species 7 with a blue-green emission at $\lambda_{\max }(\mathrm{em})=483$ $\mathrm{nm} .{ }^{19}$ To maximize the use of the color space, we also included the thienyl-extended dithienophosphole oxide $8\left(\lambda_{\max }(\mathrm{em})=545 \mathrm{ppm}\right)$ with similar photophysical properties to that of $3 .^{20}$ To our satisfaction, the new probes $\mathbf{7}$ and $\mathbf{8}$ fit well onto the parabolic fit function containing the free dithienophosphole oxide probes 1-6 from our original work, forming a representative parabolic trend in the CIE space (Figure 1).
With new probes in hand, we prepared FLAs with two representative Lewis acids $\left(\mathrm{B}\left(\mathrm{C}_{6} \mathrm{~F}_{5}\right)_{3}\right.$ and $\left.\left[\mathrm{Ph}_{3} \mathrm{C}\right]\left[\mathrm{B}\left(\mathrm{C}_{6} \mathrm{~F}_{5}\right)_{4}\right]\right)$ and found that adding more data points to the FLA parabolic fit gave diminishing improvement to the $R^{2}$ value and similarly a minimal change in standard deviation. The calculated fits generally have $\mathrm{R}^{2}$ values of 0.98 with several producing near perfect fits (see Supporting Information). This demonstrates another strength of this method; it produces highly self-consistent results. The results obtained across three, four, or five probes suggests that any combination of three could practically be used to determine the Lewis acid strength with satisfactory accuracy. Probes with similar chromaticities demonstrated nearly equal responses upon Lewis acid coordination because of their similar Lewis base character. ${ }^{17}$ Notwithstanding, the use of one or two additional probes affords the most accurate results and allows to easily check that the data are self-consistent. However, in the case when only three probes are used, emissions that span the chromaticity space (e.g., 1, 2, 3 or 1, 7, 8) are preferred over those of similar chromaticity (e.g., $\mathbf{1}, \mathbf{4}, \mathbf{5}$ or $\mathbf{4 , 6}, \mathbf{7}$ ).

In our original study, we also found that some FLAs with strong Lewis acids had emission spectra extending beyond $780 \mathrm{~nm}$ into the near-IR spectral region. ${ }^{17}$ When converted into CIE space, we were concerned that this would underestimate the strength of strong Lewis acids, as the chromaticity is based on the integral of the entire emission spectrum. However, using different sets of probes that did not generate FLAs with emissions reaching into the near-IR region revealed that this is not a major source of error for strong Lewis acids, as is evident in the LAUs determined by the refined method herein (vide infra; Supporting Information).

The second perceived shortcoming of our initial study was the fact that the LAU values obtained by extrapolation of the CIE $\mathrm{x}$-coordinate only provided a very narrow window between 0.54 and 0.77 LAUs. ${ }^{17}$ This was sufficient to distinguish between the 15 previously tested Lewis acids, but this resolution is insufficient when expanding the Lewis acid scope, as several LAUs were separated by only a fraction of a decimal. We hypothesized this being the result of only utilizing the $\mathrm{x}$-coordinates of the CIE diagram. Chromaticity defines color in a two-coordinate space; our initial method only utilized the $\mathrm{x}$-coordinate of the intercept (Figure 3a), corresponding to an ideal FLA,${ }^{17}$ leaving half of the available data out of the calculation. In order to address this issue, we decided to refine the data of our intercepts by incorporating the $y$-coordinate as well. By using both the $x$ and $y$ coordinates that define the color at the intersection point, we expect to be able to more precisely define Lewis acid strength.

As established earlier, an increasing $\mathrm{x}$-coordinate of the intercept can be correlated with increasing Lewis acid strength. ${ }^{17}$ Upon closer inspection of the original data, we also recognized that the y-coordinate decreases concurrently. We decided that a vector-based approach would be most appropriate to better exploit the information a CIE diagram provides. To be able to mathematically utilize both coordinates, the ratio of two vectors with defined magnitudes is needed. ${ }^{21}$ The most suitable origins for these vectors are at fixed points within the CIE space, at the apex and the root of the dithienophosphole oxide probe parabola, corresponding to the theoretically weakest (green) and strongest (red) possible Lewis acids, respectively (Figure $3 b$ ). One vector is generated from the apex of the probe parabola, to the intersection point with the FLA parabola, representing the "green-ness" of the ideal FLA that is used to derive the Lewis acid strength. The second vector is defined from the point 
where the probe parabola intersects with the edge of the chromaticity space (maximum $x$ ), which represents the "red-ness" of the ideal FLA. The ratio of the magnitude of the two vectors is then used to define the Lewis acid strength. Note that now as $\mathrm{x}$ increases, the Lewis acid strength increases, while an increase in y correlates with a decreasing Lewis acid strength. This two-dimensional approach consequently widens the measurable LAU range from 0 to theoretically infinity and should allow for a large number of Lewis acids to accurately be measured. In line with our initial iteration of the FLA method, the refined analysis still only requires determining the intersection point of the dithienophosphole oxide probe chromaticity curve, and the FLA chromaticity curve. Given the $\mathrm{x}$ and $\mathrm{y}$ coordinates, Equation 1 can be used to calculate the new LAU values (for step-by-step details, see the Supporting Information).

Strength $=\frac{\sqrt{(x-0.333)^{2}+(y-0.615)^{2}}}{\sqrt{(x-0.511)^{2}+(y-0.164)^{2}}} * 100$

With these improvements in hand, we sought to establish the utility and sensitivity of our method by considerably expanding the scope of Lewis acids measured in toluene. To this end, we selected probes $\mathbf{1}, \mathbf{2}, 3,7$, and $\mathbf{8}$ as probes to measure a wide variety of Lewis acids, ranging from classical main group species, to metal salts, to charged and hypervalent Lewis acids. Notably, the strength of a considerable number of the Lewis acids tested had not been determined before, for various reasons (e.g., stability, reactivity, etc.).

\section{Neutral Borane Derivatives}

Boranes are among the most popular Lewis acids by being easily synthetically accessible and highly tunable through their substituents. For example, $\mathrm{B}\left(\mathrm{C}_{6} \mathrm{~F}_{5}\right)_{3}$ has become a staple in Lewis acid catalysis as it is capable of performing a variety of selective reactions. ${ }^{22}$ However, other arylboranes of varying electron deficiency can also facilitate certain reactivity; even weak Lewis acids such as triphenylborane have been utilized in catalysis. ${ }^{23}$ In fact, a recent example by Gagné shows distinct differences in chemoselectivity when applying $\mathrm{B}\left(\mathrm{C}_{6} \mathrm{~F}_{5}\right)_{3}$ or $\mathrm{B}\left(3,5-\left(\mathrm{CF}_{3}\right) \mathrm{C}_{6} \mathrm{H}_{3}\right)_{3}$ as a Lewis acid catalyst for the reduction of natural products and sugars. ${ }^{24,25}$ However, measurements of experimental Lewis acid strength for numerous derivatives have been inconsistent. ${ }^{26}$ It is evident that due to the high popularity of boranes, applying the FLA method would be a valuable exercise. As such, we investigated a wide range of fluorinated arylboranes with different aromatic substitution patterns (Figure 4). ${ }^{27-29}$

The observed trend in Lewis acidity with the FLA method correlates with what is generally found in the literature, but our method may provide clarity for some disputed results. For instance, the FLA method indicates that $\mathrm{B}\left(\mathrm{C}_{6} \mathrm{~F}_{5}\right)_{3}$ is a stronger Lewis acid than $(\mathrm{B}(3,5$ $\left.\left(\mathrm{CF}_{3}\right)_{6} \mathrm{H}_{3}\right)_{3}$ against the dithienophosphole oxide Lewis bases used herein (Figure 5).

The relative strength of these two Lewis acids to each other has been the subject of debate in the literature and Blagg and Wildgoose explored this issue extensively with a number of different methods, including examining the reduction potential, Gutmann-Beckett, and other NMR spectroscopic techniques. ${ }^{30}$ The reduction potentials suggest that $\mathrm{B}\left(\mathrm{C}_{6} \mathrm{~F}_{5}\right)_{3}$ is a stronger Lewis acid, whereas the GB method implies the opposite. We have shown in our original study ${ }^{17}$ that the FLA PO probes are less sterically encumbered than $\mathrm{Et}_{3} \mathrm{PO}$ and therefore can better interact with bulky Lewis acids. Our method corroborates the fact that $\mathrm{B}\left(\mathrm{C}_{6} \mathrm{~F}_{5}\right)_{3}$ is the stronger Lewis acid under these conditions. Additionally, $\mathrm{B}\left(\mathrm{OC}_{6} \mathrm{~F}_{5}\right)_{3}$, which differs by only ester linkages from $\mathrm{B}\left(\mathrm{C}_{6} \mathrm{~F}_{5}\right)_{3}$, was found to be a weaker Lewis acid on our scale (Figure 5). This can be attributed to lone pair donation from the oxygen atoms to the empty p-orbital on boron.
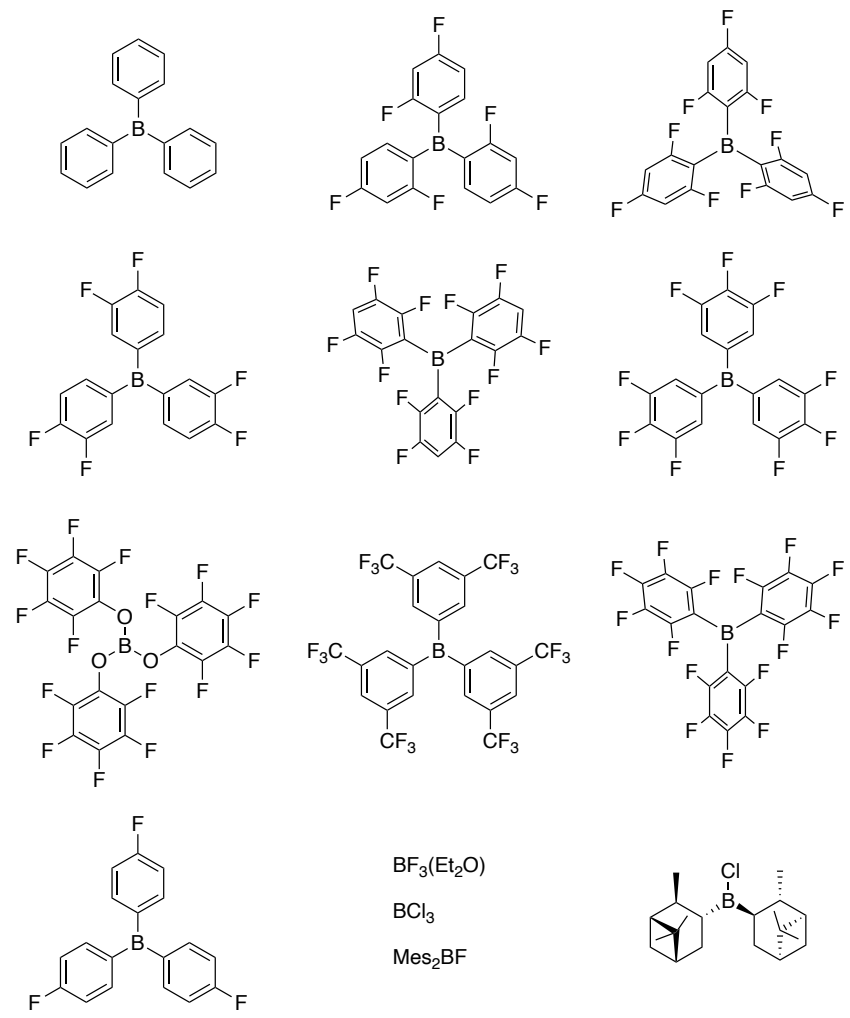

Figure 4. Borane derivatives investigated.

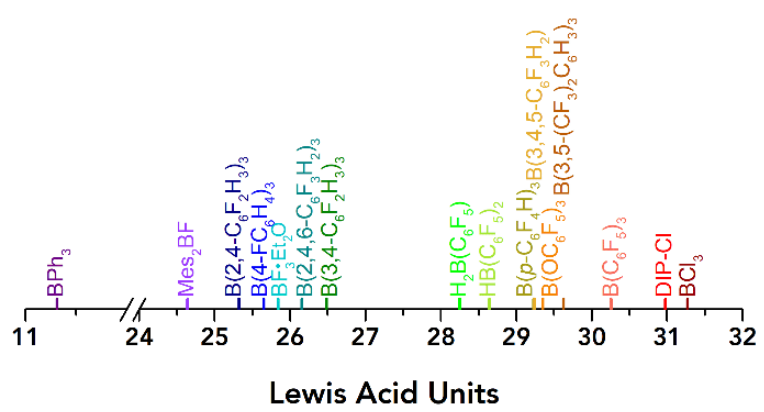

Figure 5. LAUs of neutral boranes derivatives in toluene.

The reported strength of this Lewis acid in the literature is also contradictory, as the $\mathrm{GB}$ method suggests that $\mathrm{B}\left(\mathrm{OC}_{6} \mathrm{~F}_{5}\right)_{3}$ is a stronger Lewis acid, while the Childs method implies the opposite. ${ }^{26,31,32}$ The FLA method clearly supports that $\mathrm{B}\left(\mathrm{OC}_{6} \mathrm{~F}_{5}\right)_{3}$ is the weaker Lewis acid as anticipated from the adjacent donor atoms. This is counterintuitive as one would expect the FLA method to support the results from the similar GB method, however, that is not the case. This could be for a number of reasons, including sterics, or the fundamental nature of ${ }^{31} \mathrm{P}$ NMR spectroscopy and how it is more influenced by the core-electrons distribution, whereas this has a minimal impact on the FLA method. Nevertheless, this provides support for the utility of using multiple less sterically bulky $\mathrm{P}=\mathrm{O}$ probes in the FLA method. The remaining boranes follow the expected Lewis acidity trend, based on the number and positioning of the fluorine substituents, providing strong evidence for the robustness and sensitivity of 
the FLA method. Interestingly, the distinct differences between $\mathrm{H}_{2} \mathrm{~B}\left(\mathrm{C}_{6} \mathrm{~F}_{5}\right)$ and Piers' borane $\mathrm{HB}\left(\mathrm{C}_{6} \mathrm{~F}_{5}\right)_{2}$ compared to that of $\mathrm{B}\left(\mathrm{C}_{6} \mathrm{~F}_{5}\right)_{3}$, provide a strong testament to the commonly observed dimeric nature of hydridoboranes, i.e., their apparent Lewis acidity (Figure 5). ${ }^{33,34}$ Our refined method confirmed that $\mathrm{BPh}_{3}$ is still the weakest Lewis acid against our $\mathrm{P}=\mathrm{O}$ probes in toluene ( $\mathrm{LAU}=$ 11.31). This was followed by a significant increase in strength ranging from $\mathrm{B}\left(2,4-\mathrm{C}_{6} \mathrm{~F}_{2} \mathrm{H}_{3}\right)_{3}(24.64), \mathrm{B}\left(2,4,6-\mathrm{C}_{6} \mathrm{~F}_{3} \mathrm{H}_{2}\right)_{3}$ (25.84), $\mathrm{B}(3,4-$ $\left.\mathrm{C}_{6} \mathrm{~F}_{2} \mathrm{H}_{3}\right)_{3}$ (26.41), $\mathrm{H}_{2} \mathrm{~B}\left(\mathrm{C}_{6} \mathrm{~F}_{5}\right)$ (28.25), $\mathrm{HB}\left(\mathrm{C}_{6} \mathrm{~F}_{5}\right)_{2}$ (28.64), B $(p-$ $\left.\mathrm{C}_{6} \mathrm{~F}_{4} \mathrm{H}\right)_{3}(29.23), \mathrm{B}\left(3,4,5-\mathrm{C}_{6} \mathrm{~F}_{3} \mathrm{H}_{2}\right)_{3}(29.24), \mathrm{B}\left(\mathrm{OC}_{6} \mathrm{~F}_{5}\right)_{3}(29.35)$, $\mathrm{B}\left(3,5-\left(\mathrm{CF}_{3}\right)_{2} \mathrm{C}_{6} \mathrm{H}_{3}\right)_{3}(29.63)$, to $\mathrm{B}\left(\mathrm{C}_{6} \mathrm{~F}_{5}\right)_{3}$ (30.25). Unfortunately, we could not confidently assign a $\mathrm{LAU}$ value to $\mathrm{B}\left(4-\mathrm{FC}_{6} \mathrm{H}_{4}\right)_{3}$ $\left(25.32^{*}\right)$ because it was evident in the chromaticity measurements that additional emissive species were present in solution. ${ }^{35}$

In our initial publication, we also reported the measurement of boron trihalides $\mathrm{BF}_{3} \cdot \mathrm{OEt}_{2}$ and $\mathrm{BCl}_{3}$ in toluene. The revised method provides a similarly accurate measurement of the two, with LAUs of 25.72 and 31.27 , respectively. We further explored how steric hinderance would impact haloboranes by testing $\mathrm{Mes}_{2} \mathrm{BF}$ and (-)-Bchlorodiisopinocampheylborane (DIP-Cl). The only electron-withdrawing substituent on these boranes is the singular halogen atom. Their LAUs were determined to be 22.74 and 30.98 , respectively. This nicely compares to the LAU for the other haloboranes, $\mathrm{BF}_{3} \cdot \mathrm{OEt}_{2}$ and $\mathrm{BCl}_{3}$. In both cases, the Lewis acidity of the fluoroboranes is reduced due to well-known effects of electron donation and pyramidalization energy from the F-lone pairs into the empty $\mathrm{p}$ orbital at $\mathrm{B}^{36}$

\section{Heavier Group 13 Lewis Acids}

Generally, Lewis acidity diminishes with heavier group 13 congeners. However, the trend is also strongly dependent on the substituents surrounding the Lewis acidic center. To verify the trend with a given group, we first investigated the heavy analogues of $\mathrm{B}\left(\mathrm{C}_{6} \mathrm{~F}_{5}\right)_{3}$ : $\mathrm{Al}\left(\mathrm{C}_{6} \mathrm{~F}_{5}\right)_{3}, \mathrm{Ga}\left(\mathrm{C}_{6} \mathrm{~F}_{5}\right)_{3}$, and $\operatorname{In}\left(\mathrm{C}_{6} \mathrm{~F}_{5}\right)_{3} \cdot{ }^{37,38}$ These Lewis acids are intriguing as their reactivity is drastically different - particularly $\mathrm{Al}\left(\mathrm{C}_{6} \mathrm{~F}_{5}\right)_{3}$ is known to be a highly reactive species. ${ }^{39}$ Nevertheless, the FLA method provided LAUs of 28.82, 25.65 and 22.74 for the $\mathrm{Al}, \mathrm{Ga}$, and In species, respectively. These values make all of these Lewis acids weaker than $\mathrm{B}\left(\mathrm{C}_{6} \mathrm{~F}_{5}\right)_{3}$, which agrees with the periodic trends, but conflicts with some observed experimental evidence that $\mathrm{Al}\left(\mathrm{C}_{6} \mathrm{~F}_{5}\right)_{3}$ is more reactive than $\mathrm{B}\left(\mathrm{C}_{6} \mathrm{~F}_{5}\right)_{3 .}{ }^{40} \mathrm{~A}$ possible explanation for this measurement could be the ability of $\mathrm{Al}\left(\mathrm{C}_{6} \mathrm{~F}_{5}\right)_{3}$ to form more complex adducts including those with the solvent, ${ }^{41}$ particularly given that the FLA values were determined with excess Lewis acids.

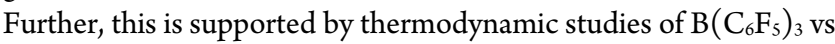
$\mathrm{Al}\left(\mathrm{C}_{6} \mathrm{~F}_{5}\right)_{3}$ in generating metallocenium ion pairs where the borane has a significantly higher methyl ion affinity. ${ }^{42}$ Subsequently, we analyzed several heavier main-group congeners with halide and triflate substituents and found that the FLA method again provides reliable results. The results were as follows: $\mathrm{AlOTf}_{3}$ (30.31), $\mathrm{GaCl}_{3}$ (29.39), $\mathrm{AlCl}_{3}$ (28.89), $\mathrm{GaOTf}_{3}$ (27.85), $\mathrm{Ga}_{2} \mathrm{Cl}_{4}$ (27.77), $\mathrm{AlBr}_{3}$ (27.28), $\operatorname{InBr}_{3}$ (27.07), $\operatorname{InOTf}_{3}(26.99)$, and $\mathrm{Ga}\left(\mathrm{NO}_{3}\right)_{3}$ (17.65) (Figure 6).

We would like to emphasize once again that our method measures the apparent Lewis acidity of these species in toluene solution (against dithienophosphole oxide Lewis bases), which does not necessarily derive from the defined molecular species in absolute terms. In these cases, it is unlikely that all of these heavier main group Lewis acids halides are in fact monomeric in solution. ${ }^{43}$ The FLA method is unique in that it can determine the effective Lewis acidity of the solution irrespective of these factors. While the determined trend does not clearly distinguish between the substituents around the center atom, it nevertheless confirms the decreasing Lewis acidity down the group. Interestingly, our method was able to probe $\mathrm{Ga}_{2} \mathrm{Cl}_{4}$, which has been shown to catalyze $\mathrm{C}-\mathrm{H}$ type activations. ${ }^{44}$ This species can be represented as either formally divalent $\mathrm{Ga}_{2} \mathrm{Cl}_{4}$ or as the mix-valent ionic $[\mathrm{Ga}]\left[\mathrm{GaCl}_{4}\right]$ and exhibits a lower LAU than that of $\mathrm{GaCl}_{3}$ (Figure 6). ${ }^{45}$ Since the obtained LAU value is close to that of $\mathrm{GaOTf}_{3}$, it may indicate that the ionic form is more likely to exist in toluene solution.

With our FLA method successfully matching the expected trends for a large group of Lewis acids so far, we then sought to push the boundaries further. We previously reported the Lewis acidity of $\mathrm{AlMe}_{3}$ ( $\mathrm{LAU}=22.73$ ) and thought it would be a highly valuable endeavor to provide some insight into the Lewis acidity of methylaluminoxane (MAO). MAO is a key co-catalyst for organometallic olefin polymerization, but the structure still remains a "black box" to date. ${ }^{46}$ The chloride-ion binding energy has previously been calculated showing that MAO will more strongly bind chloride than $\mathrm{AlMe}_{3 .}{ }^{47}$ No further experimental approaches have successfully measured the Lewis acidity of MAO. Using our FLA approach, we were able to determine the Lewis acidity of MAO in toluene, again showing the capabilities of this method. MAO has a LAU of 29.13, thus making it a stronger Lewis acid than $\mathrm{AlMe}_{3}$ (Figure 6) in a similar environment and putting it on-par with the commonly used borane co-catalysts for olefin polymerization.

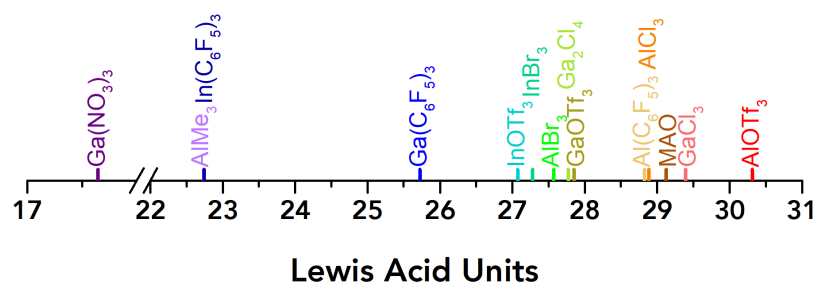

Figure 6. LAUs of heavier group 13 species in toluene.

\section{Cationic Lewis Acids}

Cationic Lewis acids are generally much stronger than their neutral counterparts. Consequently, experimentally assessing Lewis acidity (other than via in silico methods) has been met with major challenges so far. To better understand the impact of a charge on Lewis acidity, we investigated the borinium cation $\left[\mathrm{Mes}_{2} \mathrm{~B}\right]^{+}$(used as $\left.\left[\mathrm{Mes}_{2} \mathrm{~B}\right]\left[\mathrm{B}\left(\mathrm{C}_{6} \mathrm{~F}_{5}\right)_{4}\right]\right) .^{48,49}$ This stable species has been shown to possess exceptional Lewis acidity, providing unprecedented reactivity with $\mathrm{CO}_{2}$ and $\mathrm{H}_{2}$. Due to its high reactivity, the Lewis acidity of this species could not be experimentally established to date. However, we were able to clearly determine a LAU of 31.59 with our FLA method, stronger than all neutral boranes tested. This number is in line with the thermodynamic stability provided by the sterically bulky mesityl substituents. With this success, we expanded our studies to other mono- and dicationic Lewis acids. For this study, we focused mainly on exploring highly Lewis-acidic group 13, 14, and 15 species (Figure 7).

It should be noted that the group-15 Lewis acidity is derived from $\sigma^{*}$ orbitals that is distinct from the group 13 and 14 Lewis acids with empty $\mathrm{p}$ orbitals. Given these fundamental differences, we sought to explore, if the FLA method could be applied to these systems as well. 


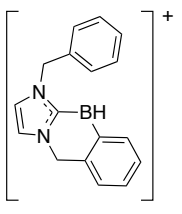

$\left[\mathrm{IBn}_{2} \mathrm{BH}\right]^{+}$

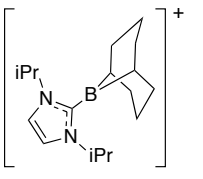

[iPrBBN] $^{+}$

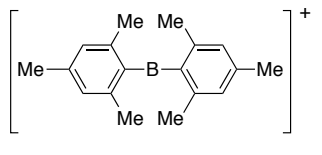

$\left[\operatorname{Mes}_{2} \mathrm{~B}\right]^{+}$

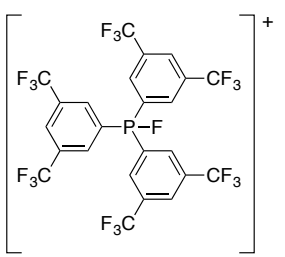

$\left[\left(3,5-\left(\mathrm{CF}_{3}\right) \mathrm{C}_{6} \mathrm{H}_{3} \mathrm{PF}\right]^{+}\right.$

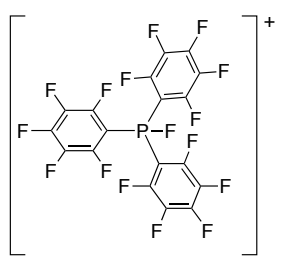

$\left[\left(\mathrm{C}_{6} \mathrm{~F}_{5}\right)_{3} \mathrm{PF}\right]^{+}$

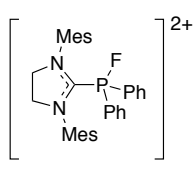

$\left[(\mathrm{SIMes}) \mathrm{PFPh}_{2}\right]^{2+}$
Figure 7. Cationic Lewis acids investigated.

In addition to $\left[\mathrm{Mes}_{2} \mathrm{~B}\right]\left[\mathrm{B}\left(\mathrm{C}_{6} \mathrm{~F}_{5}\right)_{4}\right]$, we explored two previously reported $\mathrm{N}$-heterocyclic carbene stabilized borenium cations, $\left[\mathrm{IBn}_{2} \mathrm{BH}\right]^{+} \quad(\mathrm{IBn}=1,3$-dibenzylimidazol-2-ylidene $)$ and $\left[\left(\mathrm{IiPr}_{2}\right)\left(\mathrm{BC}_{8} \mathrm{H}_{14}\right)\right]\left[\mathrm{B}\left(\mathrm{C}_{6} \mathrm{~F}_{5}\right)_{4}\right]\left([\mathrm{iPrBBN}]^{+}\right)($Figure 7$) .{ }^{50,51}$ We were able to determine that their relative Lewis acidities in toluene increase in the order: $\left[\mathrm{Mes}_{2} \mathrm{~B}\right]^{+}<\left[\mathrm{IBn}_{2} \mathrm{BH}\right]^{+}<[\mathrm{iPrBBN}]^{+}$with LAUs of $31.59,32.97$, and 34.54 respectively (Figure 8 ). Of the borenium cations, only $[\mathrm{iPrBBN}]^{+}$has previously been measured. Ingleson and co-workers explored the hydride ion affinity of a series of borenium cations at the M06-2X/6-311G(d,p) level of theory ${ }^{52}$ and noted that this Lewis acid has a higher hydride affinity than $\mathrm{B}\left(\mathrm{C}_{6} \mathrm{~F}_{5}\right)_{3}$ and our FLA method supports this in-silico result. Even though $\left[\mathrm{Mes}_{2} \mathrm{~B}\right]^{+}$has been reported to have the most unique reactivity, it is in fact, the weakest of the three boron-based cations against our $\mathrm{P}=\mathrm{O}$ Lewis bases in toluene according to the FLA method. This may be due to the significant steric protection provided by the mesityl substituents.

We also revisited several cationic group 14 Lewis acids, which were covered in our original study. $\left[\mathrm{Ph}_{3} \mathrm{C}\right]\left[\mathrm{B}\left(\mathrm{C}_{6} \mathrm{~F}_{5}\right)_{4}\right], \mathrm{Me}_{3} \mathrm{SiOTf}$, and $\left[\mathrm{Et}_{3} \mathrm{Si}\right]\left[\mathrm{B}\left(\mathrm{C}_{6} \mathrm{~F}_{5}\right)_{4}\right]$ all remain in the same relative order with the improved methodology, with LAUs of 29.47, 31.94, and 38.48, respectively. As an expansion, we then explored the Lewis acidity of other pseudo-carbocations such as $\mathrm{MeOTf}$ and $\mathrm{Me}_{3} \mathrm{SiCH}_{2} \mathrm{OTf}$. While these species are predominantly known as alkylating reagents, they could in theory still provide an estimate for the Lewis acidity of the "free" $\mathrm{CH}_{3}{ }^{+}$and $\mathrm{Me}_{3} \mathrm{SiCH}_{2}{ }^{+}$cations. Interestingly, the FLA method was able to handle these reagents and LAUs of 31.20 and 32.01 were determined, respectively (Figure 8 ). These numbers provide an interesting baseline as Lewis acids that generate higher LAUs would in theory be a stronger than simple methylating reagents in solution.

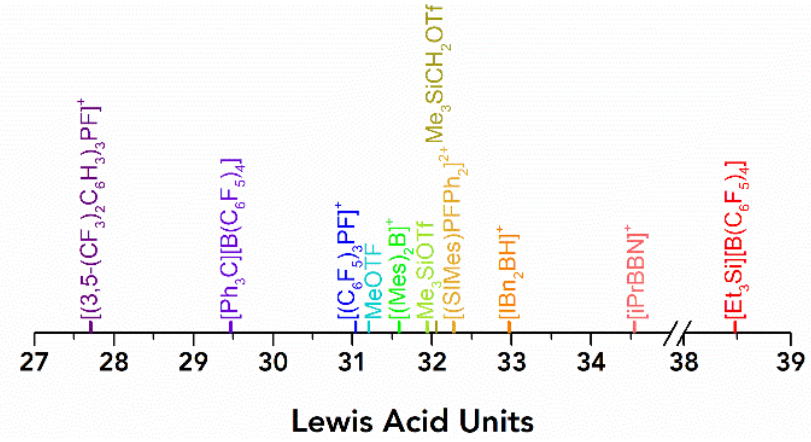

Figure 8. LAUs of cationic Lewis acids in toluene.
For group 15 Lewis acids, we focused our attention on electrophilic phosphoniums cations (EPCs). ${ }^{2}$ Due to the nature of these Lewis acids, experimentally determining the Lewis acidity has proven difficult to date. We began with $\left[\left(\mathrm{C}_{6} \mathrm{~F}_{5}\right)_{3} \mathrm{PF}\right]\left[\mathrm{B}\left(\mathrm{C}_{6} \mathrm{~F}_{5}\right)_{4}\right]$ and found a Lewis acidity of 31.04 LAU. This agrees well with the experimental data obtained so far, as it has been reported to be a stronger Lewis acid than $\mathrm{B}\left(\mathrm{C}_{6} \mathrm{~F}_{5}\right)_{3}$ but weaker than $\left[\mathrm{Et}_{3} \mathrm{Si}\right]\left[\mathrm{B}\left(\mathrm{C}_{6} \mathrm{~F}_{5}\right)_{4}\right]$. Encouragingly, we were also able to apply our method to EPCs, whose Lewis acidity could not be determined directly before. The Lewis acid $\left[\left(3,5-\left(\mathrm{CF}_{3}\right) \mathrm{C}_{6} \mathrm{H}_{3} \mathrm{PF}\right]\left[\mathrm{B}\left(\mathrm{C}_{6} \mathrm{~F}_{5}\right)_{4}\right]\right.$ was indirectly found to be a weaker Lewis acid than $\left[\left(\mathrm{C}_{6} \mathrm{~F}_{5}\right)_{3} \mathrm{PF}\right]\left[\mathrm{B}\left(\mathrm{C}_{6} \mathrm{~F}_{5}\right)_{4}\right]$, but unfortunately this Lewis acid reacts with $\mathrm{Et}_{3} \mathrm{PO} .{ }^{53}$ Gratifyingly, this Lewis acid is compatible with our FLA method - again highlighting its exceptional capabilities. $\left[\left(3,5-\left(\mathrm{CF}_{3}\right) \mathrm{C}_{6} \mathrm{H}_{3} \mathrm{PF}\right]\left[\mathrm{B}\left(\mathrm{C}_{6} \mathrm{~F}_{5}\right)_{4}\right]\right.$ was found to have a Lewis acidity of 27.57 LAU, indicating it is indeed a weaker Lewis acid than $\left[\left(\mathrm{C}_{6} \mathrm{~F}_{5}\right)_{3} \mathrm{PF}\right]\left[\mathrm{B}\left(\mathrm{C}_{6} \mathrm{~F}_{5}\right)_{4}\right]$ in toluene against our $\mathrm{P}=\mathrm{O}$ probes. Finally, with the group 15 EPCs, we also have the ability to test dicationic Lewis acids. Through a series of competition experiments the dicationic Lewis acid [(SIMes) $\left.\mathrm{PFPh}_{2}\right]\left[\mathrm{B}\left(\mathrm{C}_{6} \mathrm{~F}_{5}\right)_{4}\right]_{2}$ (SIMes $=1,3$-dimesitylimidazolidin-2-ylidene) was reported to be one of the strongest EPC Lewis acids. ${ }^{54}$ Direct measurement was previously not possible due to decomposition. Once again, the FLA method proved robust enough to measure the Lewis acidity of this highly reactive species, resulting in a LAU of 32.13 under these conditions, making it the strongest EPC investigated, supporting the literature data (Figure 8).

\section{Donor-Acceptor, Metal, and Cationic Group 16 Lewis Acids}

Lastly, we investigated the ability of the FLA method to establish the Lewis acidity of donor-acceptor Lewis acids, metals, and cationic Group 16 systems (Figure 9). Donor-acceptor Lewis acids are defined as having one or more adjacent substituents with a lone-pair that can partially quench the Lewis acidity. To evaluate the gradual reduction of Lewis acidity from neighboring donor atoms, we have tested $\mathrm{Ph}_{2} \mathrm{NBMes}_{2}$ and $\mathrm{Ph}_{2} \mathrm{PBMes}_{2}$. These species are expected to be very weak Lewis acids and periodic trends predict a stronger orbital overlap in the B-N species. This is clearly reflected by the measured Lewis acidity with LAUs of 13.86 and 14.10 for the nitrogen and phosphorus species, respectively. The difference in Lewis acidity under our experimental conditions is marginal, yet measurable. Increasing the Lewis acidity of the boron center is possible through the introduction of pentafluorophenyl substituents leading to a LAU of 15.17 for $\mathrm{Ph}_{2} \mathrm{NB}\left(\mathrm{C}_{6} \mathrm{~F}_{5}\right)_{2}$. The influence of the donor nitrogen atom can clearly be visualized by comparing the Lewis acidity to that of Piers' borane $\mathrm{HB}\left(\mathrm{C}_{6} \mathrm{~F}_{5}\right)_{2}(\mathrm{LAU}=28.64)$, confirming a considerable

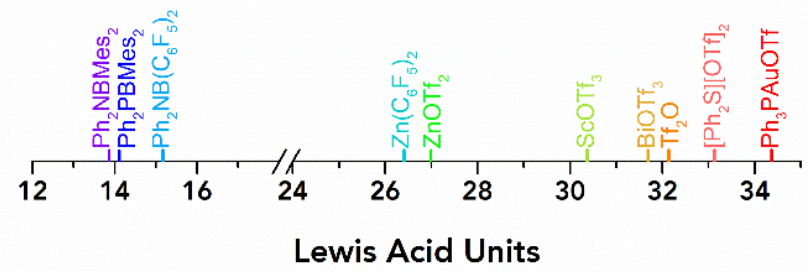

$\mathrm{N}-\mathrm{B}$ double bond character in $\mathrm{Ph}_{2} \mathrm{NB}\left(\mathrm{C}_{6} \mathrm{~F}_{5}\right)_{2}$.

Figure 9. LAUs of donor-acceptor, metal, and cationic group 16 Lewis acids in toluene. 
With this study, we did not want to neglect group 16, as some cationic chalcogens exhibit Lewis-acidic behavior as well, but they are not abundant in the literature.$^{55}$ One sulfur(IV) dicationic species in particular, which can be prepared in situ from $\mathrm{Ph}_{2} \mathrm{SO}$ and $\mathrm{Tf}_{2} \mathrm{O}$, has been found to mediate the arylation of carbonyls. ${ }^{56}$ In situ generation of the sulfuranylenium (IV) Lewis acid, $\left[\mathrm{Ph}_{2} \mathrm{~S}\right][\mathrm{OTf}]_{2}$ results in an $\mathrm{LAU}=32.05$. As a control, we also tested $\mathrm{Tf}_{2} \mathrm{O}$ (a source of the Lewis acidic $\mathrm{Tf}^{+}$) to directly generate $\mathrm{P}-\mathrm{OTf}^{+}$derivatives and compare any differences. We found that $\mathrm{Tf}_{2} \mathrm{O}(\mathrm{LAU}=32.05)$ is slightly weaker than $\left[\mathrm{Ph}_{2} \mathrm{~S}\right][\mathrm{OTf}]_{2}(\mathrm{LAU}=33.12)$ indicating we were in fact measuring the sulfuranylenium Lewis acid. It should be noted that we cannot discern whether the sulfuranylenium(IV) is of the form $\left[\mathrm{Ph}_{2} \mathrm{~S}\right][\mathrm{OTf}]_{2}$ or $\left[\mathrm{Ph}_{2} \mathrm{SOTf}\right][\mathrm{OTf}]$, but it is irrelevant in so far that the apparent Lewis acidity in solution against our $\mathrm{P}=\mathrm{O}$ Lewis bases is measured. Qualitatively, it is one of the stronger Lewis acids in our collection, and its acidity is in line with the other tested cationic species under our conditions.

Though we have primarily focused on main-group Lewis acids so far, transition metals are intrinsically Lewis acidic, but their reactivity is more complex given the complications of different redox states and accessible d orbitals. Notwithstanding, transition metals have an established reactivity. They enable many synthetic transformations and so their Lewis acidity based on our method serves as a good comparison. We therefore selected a representative mix of transition metals with either filled $(\mathrm{Zn}, \mathrm{Au})$ or empty $(\mathrm{Sc})$ d-shell configurations, as well as a catalytically active main group metal $(\mathrm{Bi})$. Zinc species such as $\mathrm{Zn}\left(\mathrm{C}_{6} \mathrm{~F}_{5}\right)_{2}(\mathrm{LAU}=26.16)$ and $\mathrm{Zn}(\mathrm{OTf})_{2}(\mathrm{LAU}=$ 26.48) show considerable Lewis acidity, but interestingly the organozinc species is slightly less Lewis acidic than the more ionic compound in toluene against our set of probes. Based on earlier observations, the $\mathrm{C}_{6} \mathrm{~F}_{5}$ motif induces high Lewis acidity and would deshield the $\mathrm{Zn}$ center more than other electron-withdrawing groups. This is an ideal contrast between inductive effects and a formal charge, as $\mathrm{Zn}(\mathrm{OTf})_{2}$ is likely accessible as a Lewis acid in the form $[\mathrm{Zn}(\mathrm{OTf})]^{+}$. On the other hand, $\mathrm{Sc}(\mathrm{OTf})_{3}(\mathrm{LAU}=30.37)$, being a $\mathrm{d}^{0}$ complex, is evidently stronger than $\mathrm{Zn}(\mathrm{OTf})_{2}$, due to the filled $\mathrm{d}$ shell in the latter (Figure 9).

Bismuth-catalyzed transformations have also been gaining recent attention. ${ }^{57}$ While technically a pnictogen, Bi nevertheless exhibits a very strong metallic character, which justifies its inclusion in this section. Recently, $\mathrm{Bi}(\mathrm{OTf})_{3}$ has found application as a water-compatible Lewis acid catalyst ${ }^{58}$ and our FLA method supports its highly Lewis acidic character in toluene with a measured LAU of 31.69. Finally, cationic gold(I) species are also garnering increased attention in a catalysis context. These have found vast application in organic synthesis, particularly in the activation of alkyne substrates. ${ }^{59}$ This activation motif requires a very strong Lewis acidic metal center and we representatively investigated the complex $\mathrm{Ph}_{3} \mathrm{PAuOTf}$ as a model compound as part of this study. To our satisfaction, we were able to determine that this is indeed a very strong Lewis acid with a LAU of 34.37 under our conditions (Figure 9). As a control to ensure that we are measuring the Lewis acidity of the cationic Au complex, we also examined the Lewis acidity of $\mathrm{Ph}_{3} \mathrm{PAuCl}$ with the FLA method, but this species was too weak to be detected (Supporting Information).

\section{Conclusion}

In conclusion, we have provided a considerable step forward for the measurement of the strength of Lewis acids in toluene against a series of $\mathrm{P}=\mathrm{O}$-based, dithienophosphole oxide Lewis bases. Our previously introduced method that leverages the red shift of Fluorescent Lewis Adducts (FLAs), provided a strong foundation toward a consistent Lewis acidity scale, but also revealed some areas for improvement, which are addressed in this article. By taking a vector-based approach that incorporates both the $\mathrm{x}$ and $\mathrm{y}$ coordinates of the CIE diagram, we were able to get more accurate measurements and concurrently better resolution for Lewis acidic species of similar strength. In order to validate our refined method, we were able to evaluate the effective Lewis acidity of an exhaustive list of species (Figure 10). These include neutral and charged main group species, transition metals, as well as unique hypervalent compounds, whose Lewis acidity is based on anti-bonding orbitals. Notably, several of the evaluated species could not be measured experimentally before, due to their high reactivity. The most notable species include MAO, $\left[\mathrm{Mes}_{2} \mathrm{~B}\right]^{+}$, as well as fluorophosphonium cations and dications. It should also be noted that our method and the reported LAU values account for the fluxional behavior of some Lewis acids in solution (such as aggregation and dissociation) by reporting the effective strength of the apparent species in solution versus a series of dithienophosphole oxide Lewis bases; and therein lies the high practical value of our method. However, it is important to note that preparing samples for this method requires scrutiny. Particularly when dealing with strongly oxidizing or reactive Lewis acids, the observed CIE coordinates could deviate from anticipated trends. Since the dithienophosphole oxide probes themselves have been demonstrated to be robust under harsh oxidative or acidic conditions, ${ }^{60,61}$ the occurrence of unexpected emission features (including white light) may be attributed to multiple emitting species in solution. As such, these FLA solutions must be prepared carefully by gradually increasing the Lewis acid equivalents to achieve saturation as detailed in the Supporting Information.

This extended study highlights the power of our method, as being able to compare very different types of Lewis acids - in terms of chemical composition and reactivity. The use of multiple probes with varying basicity allows us to overcome drawbacks of other experimental methods that measure against a single Lewis base. However, as it stands, there remain certain limitations to the methodology. We recognize that the FLA method still exclusively measures against harder $\mathrm{P}=\mathrm{O}$ donors, which may skew the results from $\mathrm{HSAB}$ interactions. This means that the resulting LAU values only apply to these specific experimental conditions. Further, we have yet to elaborate the impact of steric bulk around the Lewis acid or base in greater detail; this includes potential $\pi$-stacking interactions that could skew the binding of certain Lewis acids, and/or how solvent polarity impacts the LAU values. We continue to address these important topics to further mature the FLA approach into a more robust method. These results will be reported in due course.

\section{Experimental}

The synthesis of the dithienophosphole oxide probes has previously been reported (see SI for references). All previously known Lewis acids tested were either purchased from Sigma-Aldrich or prepared via literature procedures (see references throughout the manuscript); $\left(\mathrm{C}_{6} \mathrm{~F}_{5}\right)_{2} \mathrm{BNPh}_{2}$ is a new compound and full details can be found in the Supporting Information. 


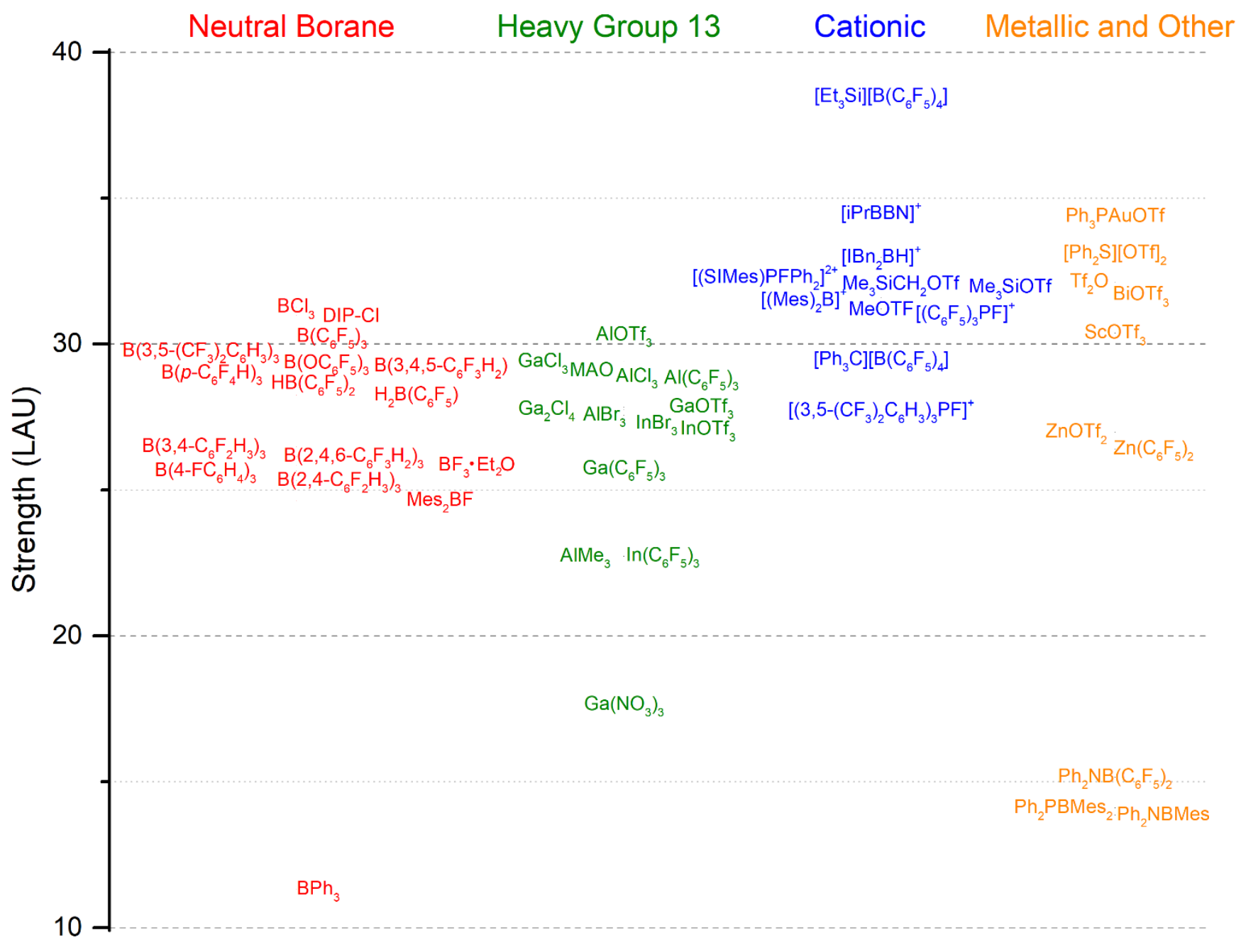

Figure 10. LAU values of all Lewis acids measured in toluene relative to one another.

All samples for optical spectroscopy measurements were prepared in an inert-atmosphere glovebox under $\mathrm{N}_{2(\mathrm{~g})}$. A $0.025 \mathrm{mM}$ stock solution of each probe was prepared by serial dilution in toluene. Lewis acids in stock solutions, such as $\mathrm{BF}_{3} \cdot \mathrm{OEt}_{2}$ and $\mathrm{BCl}_{3}$, were applied to the probe solution using Schlenk techniques, followed by cuvette sample preparation in the glovebox. All other Lewis acids were prepared to final concentrations of either $0.125 \mathrm{mM}$ or $0.25 \mathrm{mM}$ in toluene. For FLAs that required a large excess of Lewis acid to reach full saturation, their emission spectra were used to establish the number of equivalents required (see Supporting Information). Lewis acids of low solubility were added directly to the probe solutions in excess, then sonicated to form the FLAs. Following formation of the FLA, cuvettes were capped with a Teflon seal inside the glovebox and wrapped with parafilm. Optical spectroscopy measurements were performed immediately upon the removal of cuvettes from the glovebox. For a detailed step-by-step instruction on how to use the FLA method, please see the Supporting Information.

\section{ASSOCIATED CONTENT}

Experimental details, UV-VIS absorption and emission data of all FLAs, error analysis and CIE coordinates can be found in the Supporting Information. This material is available free of charge via the Internet at http://pubs.acs.org.

\section{AUTHOR INFORMATION}

\section{Corresponding Author}

*Email:caputo@yorku.ca., tbaumgar@yorku.ca

\section{Author Contributions}

The manuscript was written through contributions of all authors. All authors have given approval to the final version of the manuscript.

Notes

The authors declare no competing financial interest.

\section{ACKNOWLEDGMENT}

We are grateful to the Natural Sciences and Engineering Research Council of Canada, the Canada Foundation for Innovation, and the Canada Research Chairs program. 


\section{REFERENCES}

(1) Lewis, G. N. The Atom and the Molecule. J. Am. Chem. Soc. 1916, 38, 762-785.

(2) Caputo, C. B.; Hounjet, L. J.; Dobrovetsky, R.; Stephan, D. W. Lewis Acidity of Organofluorophosphonium Salts: Hydrodefluorination by a Saturated Acceptor. Science 2013, 341, 1374-1377.

(3) Pan, B.; Gabbaï, F. P. $\left[\mathrm{Sb}\left(\mathrm{C}_{6} \mathrm{~F}_{5}\right)_{4}\right]\left[\mathrm{B}\left(\mathrm{C}_{6} \mathrm{~F}_{5}\right)_{4}\right]$ : An Air Stable, Lewis Acidic Stibonium Salt That Activates Strong ElementFluorine Bonds. J. Am. Chem. Soc. 2014, 136, 9564-9567.

(4) Hudnall, T. W.; Kim, Y. M.; Bebbington, M. W. P.; Bourissou, D.; Gabbaï, F. P. Fluoride Ion Chelation by a Bidentate Phosphonium/Borane Lewis Acid. J. Am. Chem. Soc. 2008, 130, 10890-10891. Calorimetric Study. Can. J. Chem. 1982, 60, 809-812.

(13) Christe, K. O.; Dixon, D. A.; McLemore, D.; Wilson, W. W.; Sheehy, J. A.; Boatz, J. A. On a Quantitative Scale for Lewis Acidity and Recent Progress in Polynitrogen Chemistry. $J$. Fluor. Chem. 2000, 101, 151-153.

(14) Greb, L. Lewis Superacids: Classifications, Candidates, and Applications. Chem. Eur. J. 2018, 68, 17881-17896.

(15) Böhrer, H.; Trapp, N.; Himmel, D.; Schleep, M.; Krossing, I From Unsuccessful $\mathrm{H}_{2}$-Activation with FLPs Containing $\mathrm{B}(\mathrm{Ohfip})_{3}$ to a Systematic Evaluation of the Lewis Acidity of 33 Lewis Acids Based on Fluoride, Chloride, Hydride and Methyl Ion Affinities. Dalton Trans. 2015, 44, 7489-7499.

(16) Jupp, A. R.; Johnstone, T. C.; Stephan, D. W. The Globa Electrophilicity Index as a Metric for Lewis Acidity. Dalton Trans. 2018, 47, 7029-7035.

(17) Gaffen, J. R.; Bentley, J. N.; Torres, L. C.; Chu, C.; Baumgartner, T.; Caputo, C. B. A Simple and Effective Method of Determining Lewis Acidity by Using Fluorescence. Chem 2019, 5, 1567-1583.

(18) Baumgartner, T. Insights on the Design and Electron-Acceptor Properties of Conjugated Organophosphorus Materials. Acc. Chem. Res. 2014, 47, 1613-1622.

(19) Dienes, Y.; Eggenstein, M.; Kárpáti, T.; Sutherland, T. C.; Nyulászi, L.; Baumgartner, T. Phosphorus-Based Heteropentacenes: Efficiently Tunable Materials for Organic nType Semiconductors. Chem. Eur. J. 2008, 14, 9878-9889.

(20) Dienes, Y.; Durben, S.; Kárpáti, T.; Neumann, T.; Englert, U.; Nyulászi, L.; Baumgartner, T. Selective Tuning of the Band Gap of $\pi$-Conjugated Dithieno[3,2-b:2', $\left.3^{\prime}-d\right]$ phospholes toward Different Emission Colors. Chem. Eur. J. 2007, 13, 7487-7500.

(21) Stewart, J. Single Variable Calculus: Early Transcendentals, 8th Edition; Cengage Learning: Boston, MA, USA, 2016.

(22) Lawson, J. R.; Melen, R. L. Tris(Pentafluorophenyl)Borane and Beyond: Modern Advances in Borylation Chemistry. Inorg. Chem. 2017, 56, 8627-8643.

Mukherjee, D.; Sauer, D. F.; Zanardi, A.; Okuda, J. Selective
Metal-Free Hydrosilylation of $\mathrm{CO}_{2}$ Catalyzed by Triphenylborane in Highly Polar, Aprotic Solvents. Chem. Eur. J., 2016, 22, 7730-7733.

Bender, T. A.; Payne, P. R.; Gagné, M. R. Late-Stage Chemoselective Functional-Group Manipulation of Bioactive Natural Products with Super-Electrophilic Silylium Ions. Nature Chem. 2018, 10, 85-90.

Seo, Y.; Lowe, J. M.; Gagné, M. R. Controlling Sugar Deoxygenation Products from Biomass by Choice of Fluoroarylborane Catalyst. ACS Catal. 2019, 9, 6648-6652. Sivaev, I. B.; Bregadze, V. I. Lewis Acidity of Boron Compounds. Coord. Chem. Rev. 2014, 270-271, 75-88. Lawson, J. R.; Wilkins, L. C.; Melen, R. L. Tris(2,4,6trifluorophenyl)borane: An Efficient Hydroboration Catalyst. Chem. Eur. J. 2017, 23, 10997-11000.

Yin, Q.; Soltani, Y.; Melen, R. L.; Oestreich, M. BArF ${ }_{3-}$ Catalyzed Imine Hydroboration with Pinacolborane Not Requiring the Assistance of an Additional Lewis Base. Organometallics 2017, 36, 2381-2384.

Nicasio, J. A.; Steinberg, S.; Inés, B.; Alcarazo, M. Tuning the Lewis Acidity of Boranes in Frustrated Lewis Pair Chemistry: Implications for the Hydrogenation of Electron-Poor Alkenes. Chem. Eur. J. 2013, 19, 11016-11020.

Blagg, R. J.; Simmons, T. R.; Hatton, G. R.; Courtney, J. M.; Bennett, E. L.; Lawrence, E. J.; Wildgoose, G. G. Novel $\mathrm{B}\left(\mathrm{Ar}^{\prime}\right)_{2}\left(\mathrm{Ar}^{\prime \prime}\right)$ Hetero-Tri(Aryl)Boranes: A Systematic Study of Lewis Acidity. Dalton Trans. 2016, 45, 6032-6043.

Neu, R. C.; Ouyang, E. Y.; Geier, S. J.; Zhao, X.; Ramos, A.; Stephan, D. W. Probing Substituent Effects on the Activation of $\mathrm{H}_{2}$ by Phosphorus and Boron Frustrated Lewis Pairs. Dalton Trans. 2010, 39, 4285-4294.

Britovsek, G. J. P.; Ugolotti, J.; White, A. J. P. From B $\left(\mathrm{C}_{6} \mathrm{~F}_{5}\right)_{3}$ to $\mathrm{B}\left(\mathrm{OC}_{6} \mathrm{~F}_{5}\right)_{3}$ : Synthesis of $\left(\mathrm{C}_{6} \mathrm{~F}_{5}\right)_{2} \mathrm{BOC}_{6} \mathrm{~F}_{5}$ and $\mathrm{C}_{6} \mathrm{~F}_{5} \mathrm{~B}\left(\mathrm{OC}_{6} \mathrm{~F}_{5}\right)_{2}$ and Their Relative Lewis Acidity. Organometallics 2005, 24, 16851691.

Ménard, G.; Stephan, D. W. $\mathrm{CO}_{2}$ Reduction via Aluminum Complexes of Ammonia Boranes. Dalton Trans. 2013, 42, 5447-5453.

Piers, W. E.; Chivers, T. Pentafluorophenylboranes: From Obscurity to Applications. Chem. Soc. Rev. 1997, 26, 345-354. We confirmed that at high concentrations required to reach saturation with a weak Lewis acid, $\mathrm{B}\left(4-\mathrm{FC}_{6} \mathrm{H}_{4}\right)_{3}$ aggregates and starts to emit white light (see Supporting Information) Mück, L. A.; Timoshkin, A. Y.; Frenking, G. Design of Neutral Lewis Superacids of Group 13 Elements. Inorg. Chem. 2012 51, 640-646.

Ning, Y.; Chen, E. Y. X. Diastereospecific Ion-Pairing Polymerization of Functionalized Alkenes by Metallocene/Lewis Acid Hybrid Catalysts. Macromolecules 2006, 39, 7204-7215.

Xu, M.; Possart, J.; Waked, A. E.; Roy, J.; Uhl, W.; Stephan, D. W. Halogenated Triphenylgallium and -Indium in Frustrated Lewis Pair Activations and Hydrogenation Catalysis. Phil. Trans. R. Soc. A. 2017, 375, 20170014.

Chen, J.; Chen, E. Y.-X. Elusive Silane-Alane Complex [Si-

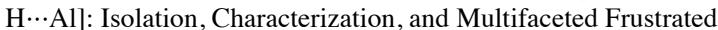
Lewis Pair Type Catalysis. Angew. Chem. Int. Ed. 2015, 54, 6842-6846.

Chen, J.; Chen, E. X. Y. Reactivity of Amine $/ \mathrm{E}\left(\mathrm{C}_{6} \mathrm{~F}_{5}\right)_{3}(\mathrm{E}=\mathrm{B}$, Al) Lewis Pairs toward Linear and Cyclic Acrylic Monomers: Hydrogenation vs. Polymerization. Molecules 2015, 20, 95759590.

Chen, M. C.; Roberts, J. A. S.; Marks, T. J. New Mononuclear and Polynuclear Perfluoroarylmetatate Cocatalysts for Stereospecific Olefin Polymerization. Organometallics 2004, 23, 932-935.

Stahl, N. G.; Salata, M. R.; Marks, T. J. B $\left(\mathrm{C}_{6} \mathrm{~F}_{5}\right)_{3^{-}}$vs $\mathrm{Al}\left(\mathrm{C}_{6} \mathrm{~F}_{5}\right)_{3^{-}}$ Derived Metallocenium Ion Pairs. Structural, Thermochemical, and Structural Dynamic Divergences. J. Am. Chem. Soc. 2005 , 127, 10898-10909.

Hog, M.; Schneider, M.; Studer, G.; Bäuerle, M.; Föhrenbacher, S. A.; Scherer, H.; Krossing, I. An Investigation of the Symmetric and Asymmetric Cleavage Products in the System Aluminum Trihalide/1-Butylimidazole. Chem. Eur. J. 2017, 23, 
11054-11066.

(44) Li, Z.; Thiery, G.; Lichtenthaler, M. R.; Guillot, R.; Krossing, I.; Gandon, V.; Bour, C. Catalytic Use of Low-Valent Cationic Gallium(I) Complexes as $\pi$-Acids. Adv. Synth. Catal. 2018, 360, 544-549.

(45) Scholz, S.; Green, J. C.; Lerner, H. W.; Bolte, M.; Wagner, M. A Novel Multidecker Sandwich Complex from the Reaction of Ferrocene with $\mathrm{GaCl}_{3}$. Chem. Commun. 2002, 1, 36-37.

(46) Chen, E. Y. X.; Marks, T. J. Cocatalysts for Metal-Catalyzed Olefin Polymerization: Activators, Activation Processes, and Structure-Activity Relationships. Chem. Rev. 2000, 100, 13911434.

(47) Yamasaki, T. Structure and Lewis Acid Sites in Alumoxane Compounds. Catal. Today 1995, 23, 425-429.

(48) Bamford, K. L.; Qu, Z. W.; Stephan, D. W. Activation of H2 and $\mathrm{Et}_{3} \mathrm{SiH}$ by the Borinium Cation $\left[\mathrm{Mes}_{2} \mathrm{~B}\right]^{+}$: Avenues to Cations $\left[\mathrm{MesB}(\mu-\mathrm{H})_{2}(\mu-\mathrm{Mes}) \mathrm{BMes}\right]^{+}$and $\left[\mathrm{H}_{2} \mathrm{~B}(\mu-\mathrm{H})(\mu-\right.$ Mes) $\left.\mathrm{B}(\mu-\mathrm{Mes})(\mu-\mathrm{H}) \mathrm{BH}_{2}\right]^{+}$. J. Am. Chem. Soc. 2019, 141, 61806184.

(49) Shoji, Y.; Tanaka, N.; Mikami, K.; Uchiyama, M.; Fukushima, T. A Two-Coordinate Boron Cation Featuring $\mathrm{C}_{-} \mathrm{B}^{+}-\mathrm{C}$ Bonding. Nature Chem. 2014, 6, 498-503.

(50) Farrell, J. M.; Hatnean, J. A.; Stephan, D. W. Activation of Hydrogen and Hydrogenation Catalysis by a Borenium Cation. J. Am. Chem. Soc. 2012, 134, 15728-15731.

(51) Farrell, J. M.; Stephan, D. W. Planar N-Heterocyclic Carbene Diarylborenium Ions: Synthesis by Cationic Borylation and Reactivity with Lewis Bases. Angew. Chem. Int. Ed. 2015, 54, 5214-5217.

(52) Clark, E. R.; Del Grosso, A.; Ingleson, M. J. The Hydride-Ion Affinity of Borenium Cations and Their Propensity to Activate $\mathrm{H}_{2}$ in Frustrated Lewis Pairs. Chem. Eur. J. 2013, 19, 2462 2466.

(53) LaFortune, J. H. W.; Szkop, K. M.; Farinha, F. E.; Johnstone, T. C.; Postle, S.; Stephan, D. W. Probing Steric Influences on Electrophilic Phosphonium Cations: A Comparison of [ 3 ,5$\left.\left.\left(\mathrm{CF}_{3}\right)_{2} \mathrm{C}_{6} \mathrm{H}_{3}\right)_{3} \mathrm{PF}\right]+$ and $\left[\left(\mathrm{C}_{6} \mathrm{~F}_{5}\right)_{3} \mathrm{PF}\right]+$. Dalton Trans. 2018, 47, 11411-11419.

(54) Holthausen, M. H.; Mehta, M.; Stephan, D. W. The Highly Lewis Acidic Dicationic Phosphonium Salt: [(SIMes) $\left.\mathrm{PFPh}_{2}\right]\left[\mathrm{B}\left(\mathrm{C}_{6} \mathrm{~F}_{5}\right)_{4}\right]_{2}$. Angew. Chem. Int. Ed. 2014, 53, 6538-6541.

(55) Stephan, D. W.; Tsao, F. A.; Waked, A. E.; Cao, L.; Hofmann, J.; Liu, L.; Grimme, S. S(VI) Lewis Acids: Fluorosulfoxonium Cations. Chem. Commun. 2016, 52, 12418-12421.

(56) Huang, X.; Patil, M.; Farès, C.; Thiel, W.; Maulide, N. Sulfur(IV)-Mediated Transformations: From Ylide Transfer to Metal-Free Arylation of Carbonyl Compounds. J. Am. Chem. Soc. 2013, 135, 7312-7323.

(57) Ollevier, T. New Trends in Bismuth-Catalyzed Synthetic Transformations. Org. Biomol. Chem. 2013, 11, 2740-2755.

(58) Kobayashi, S.; Ogawa, C. New Entries to Water-Compatible Lewis Acids. Chem. Eur. J. 2006, 12, 5954-5960.

(59) Pflästerer, D.; Hashmi, A. S. K. Gold Catalysis in Total Synthesis - Recent Achievements. Chem. Soc. Rev. 2016, 45, 1331-1367.

(60) Durben, S.; Dienes, Y.; Baumgartner, T. Cationic Dithieno[3,2$\left.b: 2^{\prime}, 3^{\prime}-d\right]$ Phospholes: A New Building Block for Luminescent, Conjugated Polyelectrolytes. Org. Lett. 2006, 8, 5893-5896.

(61) Stolar, M.; Baumgartner, T. Synthesis and Unexpected

Halochromism of Carbazole-Functionalized

Dithienophospholes. New J. Chem. 2012, 36, 1153-1160. 
